\title{
2. MAIN LAUNCH VEHICLES
}

\begin{tabular}{|c|c|c|c|c|c|}
\hline $\begin{array}{l}\text { Country/ } \\
\text { Region }\end{array}$ & Name & Type & Mass (tons) & $\begin{array}{c}\text { Payload Delivery } \\
\text { Capacity (geostation- } \\
\text { ary transfer orbit) } \\
\text { kg }\end{array}$ & $\begin{array}{l}\text { Cost (where } \\
\text { known })^{1} \\
\qquad \$ \mathrm{~m}\end{array}$ \\
\hline China & Long March & Expendable & 200 & 1400 & \\
\hline Europe & $\begin{array}{l}\text { Ariane } 3 \\
\text { Ariane } 4^{*} \\
\text { Ariane } 5^{*}\end{array}$ & $\begin{array}{l}\text { Expendable } \\
\text { Expendable } \\
\text { Expendable }\end{array}$ & $\begin{array}{c}237 \\
- \\
-\end{array}$ & $\begin{array}{l}2580 \\
2800 \\
5200\end{array}$ & $\begin{array}{c}27 \\
49 \\
-\end{array}$ \\
\hline Japan & $\begin{array}{l}\text { MU-35 } \\
\text { N2 }\end{array}$ & Expendable & $\begin{array}{c}54 \\
135\end{array}$ & $\begin{array}{c}60 \\
700\end{array}$ & - \\
\hline India & SLV-3 & Expendable & 17.5 & $-{ }^{2}$ & - \\
\hline USA & $\begin{array}{l}\text { Scout } \\
\text { Delta 3914 } \\
\text { Delta 3920 } \\
\text { Atlas F } \\
\text { Atlas G } \\
\text { Centaur } \\
\text { Titan 34D } \\
\text { Shuttle/STS }\end{array}$ & $\begin{array}{l}\text { Expendable } \\
\text { Expendable } \\
\text { Expendable } \\
\text { Expendable } \\
\text { Expendable } \\
\text { Expendable } \\
\text { Reusable }\end{array}$ & $\begin{array}{c}21.3 \\
190 \\
193 \\
140 \\
150 \\
635 \\
2,000-23,000^{4^{×}}\end{array}$ & $\begin{array}{c}2360 \\
4500 \\
\text { c. } 1400-\text { c. } 7000^{*}\end{array}$ & $\begin{array}{c}- \\
25 \\
38 \\
- \\
55 \\
100^{*} \\
10-100\end{array}$ \\
\hline USSR & $\begin{array}{l}\text { F2 } \\
\text { A2e } \\
\text { Dle (Proton) }\end{array}$ & $\begin{array}{l}\text { Expendable } \\
\text { Expendable } \\
\text { Expendable }\end{array}$ & $\begin{array}{c}185 \\
312 \\
1000\end{array}$ & $\begin{array}{c}- \\
2400 \\
9000\end{array}$ & $\begin{array}{l}- \\
- \\
25\end{array}$ \\
\hline
\end{tabular}

1. Launch costs depend on the nature of the payload and are negotiable; these costs are only a guide.

2. Capable of launching 2,000 tonne payload into low orbit.

3. Capable of launching 1,400 tonne payload into low orbit.

4. Upper stage only.

* In development. 